\title{
Research on Key Factors Influencing Surface Subsidence of Paste Backfilling Mining in Thick Coal Seam of Deep Mine
}

\author{
Meng Zhang $\mathbb{D}^{1},{ }^{1}$ Hui He, ${ }^{1}$ Xin Jin $\mathbb{D}^{1},{ }^{1}$ Yonglong Qu $\mathbb{D},{ }^{1}$ and Hongjun Guo $\mathbb{D}^{2}$ \\ ${ }^{1}$ School of Civil \& Architecture Engineering, Xi'an Technological University, Xi'an 710021, China \\ ${ }^{2}$ Jiangsu Vocational Institute of Architectural Technology, Xuzhou 221116, China \\ Correspondence should be addressed to Meng Zhang; zhangmeng@xatu.edu.cn
}

Received 25 December 2020; Accepted 26 May 2021; Published 7 June 2021

Academic Editor: Hualei Zhang

Copyright (c) 2021 Meng Zhang et al. This is an open access article distributed under the Creative Commons Attribution License, which permits unrestricted use, distribution, and reproduction in any medium, provided the original work is properly cited.

The research on the key factors of surface subsidence in paste backfilling mining of thick coal seam in deep mine is a complex system engineering, which involves mining, backfilling, support, subsidence, safety, and other aspects. At present, there is no systematic research on the key factors of surface subsidence in paste backfilling mining of thick coal seam more than 6 meters in a deep mine. In this paper, field research, laboratory experiments, theoretical analysis, and other research methods are used to carry out the research about 3\# coal seam under buildings in the Lu'an area. The main conclusions are as follows: through the construction of the fuzzy extension model of surface subsidence in paste backfilling mining, five types of surface subsidence are obtained, including overburden structure, roof subsidence before backfilling, nonbackfilling account, the strength of filling body, and backfilling technology. It is the key factor to control the surface subsidence; the optimization measures are given to provide a reference for the reasonable design of paste backfilling mining in other working faces. The research conclusion has a certain reference value for solving a series of problems such as coal resources under buildings, solid waste disposal, controlling strata and surface movement, improving the recovery rate of mine resources, and extending the service life of mine.

\section{Introduction}

Paste backfilling mining in coal mines can effectively solve the serious waste of resources, low recovery rate, and ecological and environmental damage caused by high-intensity mining, which is an important technical means to realize the sustainable development of coal mine production [1-4]. In 1979, paste backfilling was first carried out in Germany for the purpose of waste treatment. Due to fewer resources, the technology has not been further developed [5-8]. In 2006, it was the first industrial test of paste backfilling mining in China. At present, the technology has been applied to nearly 20 pairs of mines in 6 mining areas in China, realizing green mining. Practice has proved that the effect of paste backfilling is good, but the technology still has some prominent problems, such as low production of filling face, not suitable for deep mine thick seam paste backfilling mining, high filling cost, and so on, which seriously restricts the wide application of the technology. Therefore, it is urgent to study the paste backfilling technology of thick coal seam in a deep mine.

Mining scholars and industry workers have carried out a lot of research on strata control and overlying strata migration law of filling mining in coal seam more than 6 meters in deep mine [9-14]. Mining technology under buildings has been developed for many years at home and abroad and has made a lot of systematic achievements in rock stratum control and surface subsidence of paste backfilling mining [15-17], but the research on surface subsidence of paste backfilling mining with large mining height above 6 meters is relatively few. As for the surface subsidence problem of paste backfilling, the traditional methods are mostly based on the equivalent mining height and probability integral method to predict, without considering the limit conditions such as too low paste backfilling rate, too large undercutting amount, and insufficient support strength, which may also lead to roof fracture. In this case, there is no relevant special theoretical research on how to predict surface subsidence. In 
addition, there are few research studies on the combination of rock control and filling mining technology and method; that is, the current theoretical research lags behind the field practice of filling technology.

At present, with the deepening of the research on the influencing factors of paste backfill mining, many evaluation methods have been put forward, such as the analytic hierarchy process and the neural network method. However, it is difficult to effectively solve the problem of the combination of qualitative and quantitative indicators by sticking to a single evaluation method or model, and the evaluation results are often uncertain and fuzzy. The trend and direction of filling mining theory research and development should be based on the different production practices in the mining area. To solve the above problems, these methods are improved. Usually, different evaluation methods are combined and combined with their advantages to build a combination evaluation model.

Extenics is a new discipline that aims to study the possibility of business expansion and the rules and methods of innovation by using formal models. It was first proposed by Chinese scholar Cai et al. [18, 19]. It can unify quantitative analysis and qualitative analysis, which is suitable for mathematical measurement under the condition of limited information, and can reasonably reflect the development of evaluation objects. It is feasible to evaluate the influence factors of coal seam filling mining. In this paper, the fuzzy extension model is used to study the key factors of surface subsidence in deep mine thick seam paste backfilling mining, and the improvement measures are put forward.

\section{Fuzzy Extension Analysis on Key Factors of Surface Subsidence in Paste Backfilling Mining}

From the surface subsidence coefficient, we can see that the factors affecting the filling mining are affected by the mining technical conditions, roof and floor displacement, backfilling body parameters, and mining and backfilling technology, including both qualitative and quantitative indicators, and have variability, randomness, and fuzziness. In this section, combined with the characteristics of surface subsidence factors, a fuzzy extension analysis model will be established to find out the key factors and evaluate the stability and reliability of paste backfilling mining to control surface subsidence.

\subsection{Evaluation Index of Key Factors of Surface Subsidence in} Paste Backfilling Mining. The matter element system diagram of the key factors of surface subsidence in paste filling mining, namely, the evaluation index system, is shown in Figure 1.

\subsection{Fuzzy Extension Evaluation Model}

2.2.1. Fuzzy Matter Element. The concept of matter element is introduced by extenics, $R=$ (thing, feature, quantity) $=(N$, $c, v)$, in which thing $N$, feature $c$, and thing $v$ form a triple. Matter element correctly reflects the relationship between quality and quantity and is the logical cell of extenics [20-22]. If $N$ is characterized by $c_{1}, c_{2}, \ldots, c_{n}$ and the corresponding fuzzy values $v_{1}, v_{2}, \ldots, v_{n}$, then $R$ is called n-dimensional fuzzy matter element, $R=(N, c, v)$. If the $n$ dimensional matter elements of $m$ objects are combined, the $n$-dimensional compound matter element $R_{m n}$ of $m$ objects is formed.

If the value of $R_{m n}$ is rewritten as the value of fuzzy matter element, it is called the $n$-dimensional compound fuzzy matter element of $m$ objects, recorded as

$$
R_{m n}=\left[\begin{array}{ccccc} 
& M_{1} & M_{2} & \cdots & M_{m} \\
c_{1} & v_{11} & v_{21} & \cdots & v_{m 1} \\
c_{2} & v_{12} & v_{22} & \cdots & v_{m 2} \\
\cdots & \cdots & \cdots & \cdots & \cdots \\
c_{n} & v_{1 n} & v_{2 n} & \cdots & v_{m n}
\end{array}\right] \text {, }
$$

where $R_{m n}$ is the $n$-dimensional compound fuzzy matter element of $m$ objects, $M_{i}$ is the $i$-th object $(i=1,2, \ldots, m), C_{i}$ is the $j$-th feature $(j=1,2, \ldots, n)$, and $V_{i j}$ is the membership degree corresponding to the $j$-th feature of the $i$-th object.

2.2.2. Fuzzy Membership Degree. To effectively determine the stability level of the key factors causing surface subsidence, its evaluation criteria must be established. It can be seen from Figure 1 that there are quantitative and qualitative indexes in the evaluation indexes of key factors of surface subsidence in paste filling mining, while the fuzzy membership function has great advantages in quantitative processing of qualitative indexes.

(1) Fuzzy Membership Degree of Qualitative Index

The fuzzy membership function is determined by expert scoring to obtain the membership degree of the secondary qualitative indicators. Further, by virtue of the weight between the indicators, the comprehensive membership degree of the primary qualitative indicators is obtained according to the weighted average calculation results. People are subjective, so are experts. Then, in the actual scoring process, we usually take multiple $(>5)$ experts to evaluate the results and then screen them. After removing the abnormal values, we take the average value as the result, to be consistent with the situation on-site as much as possible. The 10-point system is a common scoring method and means. Therefore, the specific scoring principles are shown in Table 1.

As shown in the following formula, the fuzzy membership degree is calculated according to the characteristics of each index.

$$
\left\{\begin{array}{l}
\mu_{i j}=\frac{\mu_{i j}}{\max \mu_{i j}}, \text { the bigger, the better, } \\
\mu_{i j}=\frac{\min \mu_{i j}}{\mu_{i j}}, \quad \text { the smaller, the better, }
\end{array}\right.
$$




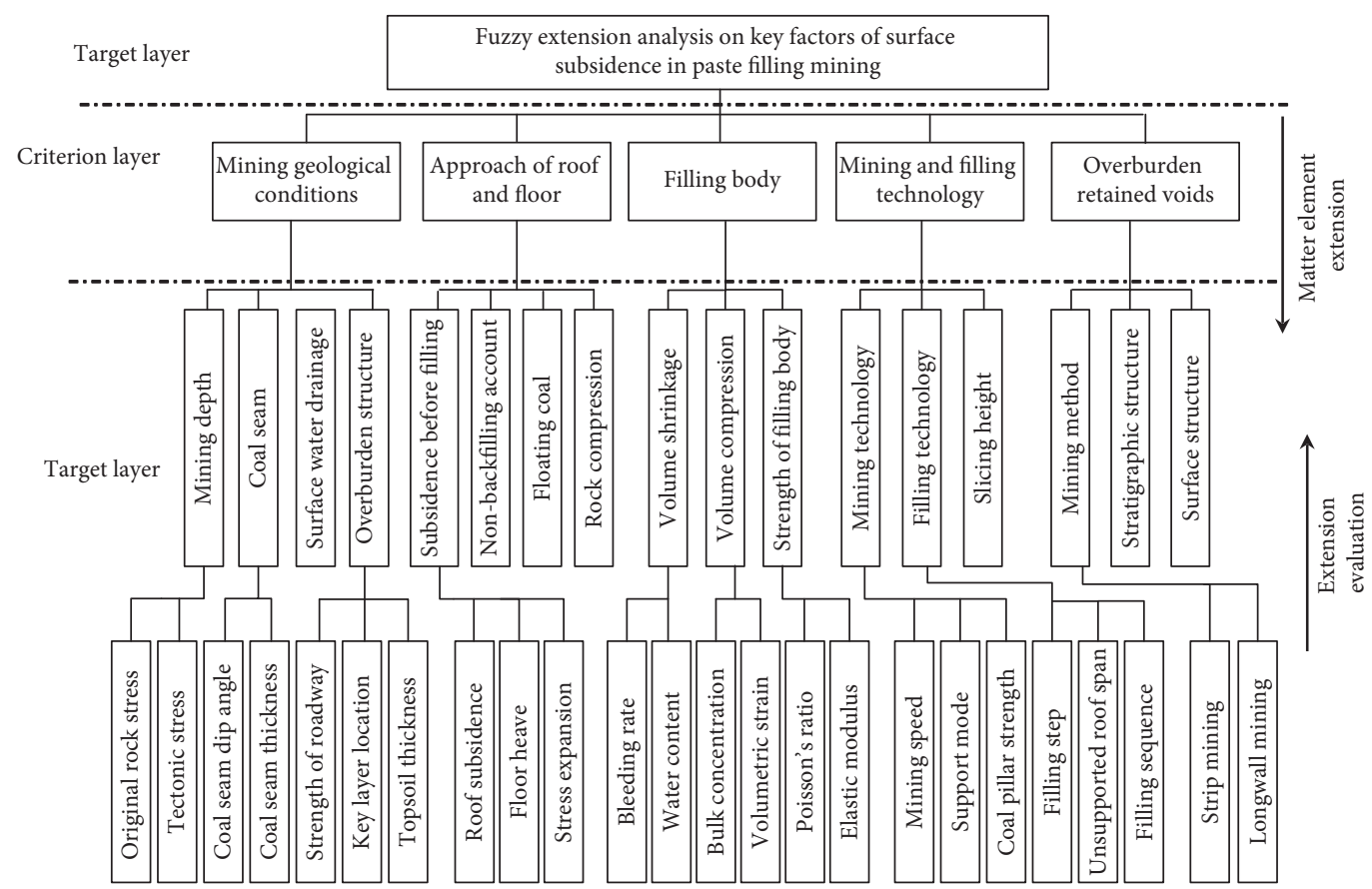

Figure 1: Evaluation index of key factors of surface subsidence in paste backfilling mining.

Table 1: Point system.

\begin{tabular}{lccccc}
\hline Influence degree & Slight & Lighter & Secondary & Little serious & Serious \\
\hline Score & $0 \sim 2$ & $2 \sim 4$ & $4 \sim 6$ & $6 \sim 8$ & $8 \sim 10$ \\
\hline
\end{tabular}

where $\mu_{i j}$ is the fuzzy membership degree, and $\max \mu_{i j}$ and $\min \mu_{i j}$ are the maximum and minimum values of the characteristic values of each evaluation index in each object.

The comprehensive membership degree of the first level qualitative index is calculated as follows:

$$
\mu=\sum_{i=1}^{k} \omega_{i j} \cdot \mu_{i j}
$$

where $\omega_{i j}$ is the weight of the $j$-th secondary qualitative index of the $i$-th object and $K$ is the number of secondary qualitative indexes.

(2) Fuzzy Membership Degree of Quantitative Index The determination method is shown in Table 2.

\subsubsection{Association Analysis}

(1) Determine the matter element to be evaluated (a) Matter element to be evaluated

$$
\mathbf{R}=\left[\begin{array}{ccc}
p & c_{1} & v_{1} \\
& c_{2} & v_{2} \\
& \ldots & \ldots \\
& c_{n} & v_{n}
\end{array}\right]
$$

where $v_{i}(i=1,2, \ldots, n)$ is the quantity value of matter element $p$ with respect to the $i$-th evaluation index $c_{i}$.

(b) Furthermore, the classical domain and node domain of the criterion layer can be obtained Order

$$
\begin{aligned}
\mathbf{R}_{0 j}=\left(N_{0 j}, \mathbf{C}, \mathbf{V}_{0 j}\right) & =\left[\begin{array}{ccc}
N_{0 j} & c_{1} & V_{0 j 1} \\
& c_{2} & V_{0 j 2} \\
& \ldots & \ldots \\
& c_{n} & V_{0 j n}
\end{array}\right] \\
& =\left[\begin{array}{ccc}
N_{0 j} & c_{1} & \left\langle a_{0 j 1}, b_{0 j 1}\right\rangle \\
& c_{2} & \left\langle a_{0 j 2}, b_{0 j 2}\right\rangle \\
\ldots & \ldots \\
& c_{n} & \left\langle a_{0 j n}, b_{0 j n}\right\rangle
\end{array}\right],
\end{aligned}
$$


TABle 2: Fuzzy membership degree of quantitative indicators.

\begin{tabular}{|c|c|c|}
\hline No & Quantitative index & Fuzzy membership degree \\
\hline 1 & Mining depth & $\begin{array}{c}\text { When the mining depth is greater than } 800 \text {, the membership degree is } 0 \text {, less than } 200 \text { is } 1 \text {, and the middle is } \\
0.5 \text {. }\end{array}$ \\
\hline 2 & Coal seam & $\begin{array}{l}\text { When the dip angle of the coal seam is greater than } 54^{\circ} \text {, the membership degree is } 0 \text {; when the dip angle of the } \\
\text { coal seam is } 0^{\circ} \text {, the membership degree is } 1 .\end{array}$ \\
\hline 3 & Overburden structure & $\begin{array}{l}\text { When the uniaxial compressive strength (unit: } \mathrm{MPa}) \in(40,80) \text { (hard overburden), the membership degree is } \\
0.3 \text {; when } \in(20,40) \text { (medium hard overburden), the membership degree is } 0.5 \text {; when } \in(10,20) \text { (weak } \\
\text { overburden), the membership degree is } 0.7 \text {; when }<10 \text { (very weak overburden), the membership degree is } 0.9 \text {. }\end{array}$ \\
\hline 4 & $\begin{array}{l}\text { Subsidence before } \\
\text { filling }\end{array}$ & $\begin{array}{c}\text { When the roof has no subsidence, the membership degree is taken as } 1 \text {; when the roof is larger than } 100 \mathrm{~mm} \text {, } \\
\text { it is taken as } 0 .\end{array}$ \\
\hline 5 & $\begin{array}{l}\text { Nonbackfilling } \\
\text { account }\end{array}$ & $\begin{array}{l}\text { When there is no subsidence, the membership degree is taken as } 1 \text {; when it is greater than } 60 \mathrm{~mm} \text {, it is taken as } \\
0\end{array}$ \\
\hline 6 & Floating coal & $\begin{array}{c}\text { When there is no compression, the membership degree is } 1 \text {; when the compression is greater than } 50 \mathrm{~mm} \text {, the } \\
\text { membership degree is } 0 .\end{array}$ \\
\hline 7 & Rock compression & $\begin{array}{c}\text { When there is no compression, the membership degree is } 1 \text {; when the compression is greater than } 50 \mathrm{~mm} \text {, the } \\
\text { membership degree is } 0 .\end{array}$ \\
\hline 8 & Volume shrinkage & When there is no shrinkage, the membership degree is 1 ; when it is greater than $30 \mathrm{~mm}$, it is 0 . \\
\hline 9 & Volume compression & $\begin{array}{c}\text { When there is no compression, the membership degree is } 1 \text {; when the compression is greater than } 50 \mathrm{~mm} \text {, the } \\
\text { membership degree is } 0 .\end{array}$ \\
\hline 10 & Strength of filling body & $\begin{array}{l}\text { When the strength is greater than } 5 \mathrm{MPa} \text {, the membership degree is } 0 \text {; when the strength is less than } 1 \mathrm{MPa} \text {, } \\
\text { the membership degree is } 1 .\end{array}$ \\
\hline 11 & Slicing height & $\begin{array}{c}\text { When the slice mining height is greater than } 5 \mathrm{~m} \text {, the membership degree is } 0 \text {; when the slice mining height is } \\
\text { less than } 1 \mathrm{~m} \text {, the membership degree is } 1 .\end{array}$ \\
\hline
\end{tabular}

where $R_{0 j}$ is the matter element and $N_{0 j}$ is the $j$-th evaluation category; $c_{i}(i=1,2, \ldots, n)$ is the $i$-th evaluation index; $V_{0 j i}(j=1,2, \ldots, m)$ is the value range of the $i$-th evaluation index $c_{i}$ in the $j$-th evaluation category, that is, the data range of the index $c_{i}$ classic domain, and there is $V_{0 j i}=\left\langle a_{0 j i}, b_{0 j i}\right\rangle$.

Order

$$
\begin{aligned}
\mathbf{R}_{P} & =\left(P, \mathbf{C}, \mathbf{V}_{P}\right)=\left[\begin{array}{ccc}
P & c_{1} & V_{P 1} \\
& c_{2} & V_{P 1} \\
\ldots & \ldots \\
& c_{n} & V_{P n}
\end{array}\right] \\
& =\left[\begin{array}{ccc}
P & c_{1} & \left\langle a_{P 1}, b_{P 1}\right\rangle \\
& c_{2} & \left\langle a_{P 2}, b_{P 2}\right\rangle \\
\ldots & \ldots \\
& \ldots & \left\langle a_{P n}, b_{P n}\right\rangle
\end{array}\right],
\end{aligned}
$$

where $P$ is the whole of the evaluation categories; $V_{P i}(i=1,2, \ldots, n)$ is the value range of $P$ with respect to the $i$-th evaluation index $c_{i}$, that is, the nodal region of $P$.

(2) The solution of correlation degree

$$
K_{j}\left(v_{i}\right)= \begin{cases}-\frac{\rho\left(v_{i}, v_{0 j i}, V_{0 j i}\right)}{\left|b_{0 j i}-a_{0 j i}\right|}, & v_{i} \in V_{0 j i}, \\ \frac{\rho\left(v_{i}, v_{0 j i}, V_{0 j i}\right)}{\rho\left(v_{i}, V_{P i}\right)-\rho\left(v_{i}, V_{0 j i}\right)}, & v_{i} \notin V_{0 j i},\end{cases}
$$

where $\rho\left(v_{i}, v_{0 j i}, V_{0 j i}\right)$ is the lateral distance between point $v_{i}$ and interval $v_{0 j i}$ with $V_{0 j i}$ as the optimal value. The lateral distance is divided into left distance and right distance, which are calculated according to equations (8) and (9), respectively; $\rho\left(v_{i}, V_{0 j i}\right)$ and $\rho\left(v_{i}, V_{P i}\right)$ are the lateral distances between point $v_{i}$ and interval $V_{0 j i}$ and $V_{P i}$, which are calculated according to equations (10) and (11) respectively.

$$
\begin{aligned}
& \rho\left(v_{i}, v_{0 j i}, V_{0 j i}\right)= \begin{cases}a_{0 j i}-v_{i}, & v_{i} \leq a_{0 j i}, \\
v_{i}-b_{0 j i}, & v_{i} \geq v_{0 j i}, \\
\frac{\left(b_{0 j i}-v_{0 j i}\right) \cdot\left(v_{i}-a_{0 j i}\right)}{a_{0 j i}-v_{0 j i}}, & v_{i} \in\left\langle a_{0 j i}, v_{0 j i}\right\rangle,\end{cases} \\
& \rho\left(v_{i}, v_{0 j i}, V_{0 j i}\right)= \begin{cases}a_{0 j i}-v_{i}, & v_{i} \leq v_{0 j i}, \\
\frac{\left(a_{0 j i}-b_{0 j i},\right.}{\left.b_{0 j i}\right) \cdot\left(b_{0 j i}-v_{i}\right)}, & v_{i} \geq b_{0 j i},\end{cases}
\end{aligned}
$$

$$
\begin{aligned}
& \rho\left(v_{i}, V_{0 j i}\right)=\left|v_{i}-\frac{a_{0 j i}+b_{0 j i}}{2}\right|-\frac{b_{0 j i}-a_{0 j i}}{2}, \\
& \rho\left(v_{i}, V_{P i}\right)=\left|v_{i}-\frac{a_{P i}+b_{P i}}{2}\right|-\frac{b_{P i}-a_{P i}}{2} .
\end{aligned}
$$


(3) Determination of evaluation index weight for key factors of surface subsidence in paste backfilling mining

The analytic hierarchy process is selected here to determine the weight.

Let the element $C$ of the upper layer be the criterion, let the elements of the next layer be $u_{1}, u_{2}, \ldots, u_{n}$, and let the relative weights of each element to criterion $C$ be $\omega_{1}, \omega_{2}, \ldots, \omega_{n}$. The main process of determining the weight of the evaluation index based on the analytic hierarchy process (AHP) is as follows:

(a) Construction of pairwise comparison matrix According to the scale of $1-9$, the importance degree of elements $u_{i}$ and $u_{j}$ is assigned to qualitatively reflect which is more important. The meaning of proportional scale is shown in Table 3 .

Through pairwise comparison, a paired comparison judgment matrix $\mathbf{A}=\left(a_{i j}\right)_{n \times n}$ is obtained, where $a_{i j}$ is the proportional scale of the importance of elements $u_{i}$ and $u_{j}$ relative to $C$. The judgment matrix $\mathbf{A}$ has the following properties: $a_{i j}>0, a_{j i}=1 / a_{i j}, a_{i i}=1$.

(b) Weight calculation by eigenvalue method Solve the eigenvalue of judgment matrix $\mathbf{A}$; that is, the following formula is satisfied:

$$
\mathbf{A W}=\lambda_{\max } \mathbf{W},
$$

where $\lambda_{\max }$ is the largest eigenvalue of $\mathbf{A}$, and $\mathbf{W}$ is the corresponding eigenvector. After normalization, $\mathbf{W}$ can be used as the weight vector $\left[\omega_{1}, \omega_{2}, \ldots, \omega_{n}\right]^{T}$.

(c) Consistency test

(i) Calculate the consistency index (CI)

$$
\mathrm{CI}=\frac{\lambda_{\max }-n}{n-1},
$$

where $n$ is the order of matrix $\mathbf{A}$, that is, the number of evaluation indexes.

(ii) Find the corresponding average random consistency index RI

Table 4 gives the average random consistency index of order 1-15.

(iii) Calculate the consistency ratio $\mathrm{CR}$

$$
\mathrm{CR}=\frac{\mathrm{CI}}{\mathrm{RI}} \text {. }
$$

When CR is less than 0.1, the consistency of the judgment matrix is acceptable; otherwise, repeat steps (1) (3) after making an appropriate correction to the judgment matrix until the consistency test is met.

(4) Calculation of correlation degree

Relevance degree $K$ is a measure to describe the relevance between things. Calculate the correlation degree of matter element $p$ to be evaluated with

\begin{tabular}{|c|c|}
\hline $\begin{array}{l}\text { Proportional } \\
\text { scale }\end{array}$ & Meaning \\
\hline 1 & The weights of $u_{i}$ and $u_{j}$ are the same \\
\hline 3 & The weight of $u_{i}$ is greater than $u_{j}$ \\
\hline 5 & The weight of $u_{i}$ is larger than that of $u_{j}$ \\
\hline 7 & The weight of $u_{i}$ is stronger than that of $u_{j}$ \\
\hline 9 & $\begin{array}{c}\text { The weight of } u_{i} \text { is significantly higher than that } \\
\text { of } u_{j}\end{array}$ \\
\hline $2,4,6,8$ & The median of $1,3,5,7$, and 9 \\
\hline Reciprocal & $\begin{array}{l}\text { If the ratio of } u_{i} \text { and } u_{j} \text { is } a_{i j} \text {, the ratio of } u_{j} \text { and } \\
\qquad u_{i} \text { is } 1 / a_{i j}\end{array}$ \\
\hline
\end{tabular}
respect to grade $j$.
TABLE 3: The meaning of proportion quotient.

TABLE 4: RI value table.

\begin{tabular}{lc}
\hline$n$ & $\mathrm{RI}$ \\
\hline 1 & 0 \\
2 & 0 \\
3 & 0.52 \\
4 & 0.89 \\
5 & 1.12 \\
6 & 1.26 \\
7 & 1.36 \\
8 & 1.41 \\
9 & 1.46 \\
10 & 1.49 \\
11 & 1.52 \\
12 & 1.54 \\
13 & 1.56 \\
14 & 1.58 \\
15 & 1.59 \\
\hline
\end{tabular}

$$
K_{j}(p)=\sum_{i=1}^{n} \omega_{i} K_{j}\left(v_{i}\right)
$$

(5) Determine the evaluation level

According to the expert experience and corresponding standards and based on the evaluation index value principle and value range, the stability grade of surface subsidence in paste backfilling mining is divided into five grades, namely, good stability (grade I), fairly good stability (grade II), general stability (grade III), relatively poor stability (grade IV), and poor stability (grade V). The evaluation criteria are shown in Table 5.

Therefore, if

$$
K_{j_{0}}(p)=\max _{j_{0} \in\{1,2, \ldots, m\}}\left(K_{j}(p)\right),
$$

then the matter element $p$ belongs to grade $j_{0}$.

\section{Study on the Influence of the Key Factors of Surface Subsidence in Paste Backfilling Mining}

3.1. Analysis on Key Factors of Surface Subsidence in Paste Backfilling Mining. According to the above established fuzzy extension analysis model and evaluation index, we calculate 
TABLE 5: Evaluation guidelines.

\begin{tabular}{lcc}
\hline Stability grades & Membership degree & Meaning of each grade \\
\hline I & $0.8 \sim 1.0$ & Good stability \\
II & $0.6 \sim 0.8$ & Fairly good stability \\
III & $0.4 \sim 0.6$ & General stability \\
IV & $0.2 \sim 0.4$ & Relatively poor stability \\
V & $0 \sim 0.2$ & Poor stability \\
\hline
\end{tabular}

the fuzzy membership degree of the index, establish the fuzzy matter element to be evaluated, determine the classical domain and node domain, determine the weight, calculate the correlation degree, and comprehensively evaluate the key factors and reliability of the surface subsidence of paste backfilling mining. Limited to the length of the article, the calculation process directly gives the weight value and the final overall evaluation; the results are shown in Table 6.

Through the calculation of single index and multi-index correlation degree, the correlation degree of mining geological conditions, roof and floor approach, mining and backfilling technology, and overburden retained gap of the criterion layer and the target layer is determined. The results show that the stability and reliability of surface subsidence of paste backfilling mining are "good," and the key factors are the overburden structure, the roof subsidence before backfilling, nonbackfilling account, the strength of the filling body, and the backfilling technology. At the same time, it is also the main reason that the control stability of surface subsidence is "good."

3.2. Technical Path and Improvement Measures. To sum up, combined with theoretical research and production practice, the technical path of controlling surface subsidence by backfilling mining is mainly to control the four aspects of mining geological conditions, roof and floor approaching amount, filling body, and overburden retained gap, especially the five key factors of overburden structure, roof subsidence before backfilling, nonbackfilling account, filling body strength, and backfilling technology. But for example, in mining geological conditions, such as overburden structure, it is a given factor for a certain mine. Although mining depth, coal seam thickness, key layer position, and so on all have greater weight, which has a great impact on surface subsidence, they are all internal factors that cannot be changed. Therefore, this paper proposes to control the surface subsidence of paste backfilling mining from the following technical approaches and external key factors affecting the movement of overlying strata.

\subsubsection{Control of Roof Subsidence after Mining and before} Paste Backfilling. The roof subsidence before backfilling after mining is composed of three parts: roof subsidence, floor heave, and stress expansion of roof and floor rock strata, which is mainly influenced by time interval, roof pressure, unsupported roof span, and working face length. At present, in the paste backfilling mining, we should try to shorten the time interval after mining and before backfilling, shorten unsupported roof span, improve the active support force of the support, parallel mining and backfilling operation as far as possible, and avoid designing long working face mining to reduce and control the roof subsidence before backfilling after mining.

3.2.2. Increase of Backfilling Rate. The backfilling rate of goaf is divided into plane backfilling rate and top connection rate of the filling body. To increase the backfilling rate is to increase the backfilling plane to make it fully filled and to increase the height of contact with the roof to make it fully contacted. The lower the plane backfilling rate, especially the honeycomb backfilling, the more serious the surface subsidence. The reason for the low amount of contact between the backfill and roof is mostly due to the limitation of low backfilling technology and insufficient backfilling materials.

Increasing the backfilling rate is the most effective measure to reduce the surface subsidence, but it will increase the cost of backfilling mining. In the actual production, improving the backfilling technology, strengthening the monitoring, and even secondary grouting can avoid honeycomb backfilling, make the filling material fill the whole roof gap, reduce the potential roof subsidence space, and make the filling body fully supported to achieve the purpose of reducing subsidence control.

For the compensation of nonbackfilling account, the sealing of filling space in goaf should be strengthened in time to improve the liquid level of filling slurry. In addition, the support strength should be ensured to prevent the phenomenon of sinking net pocket and false top roof connection. For the new backfilling mining face, advance planning, reasonable design of roadway location, support mode, and coal pillar size, the working face implement inclined mining and inclined backfilling.

3.2.3. Improvement of the Physical and Mechanical Properties of Backfilling Slurry and Filling Body. In paste backfilling mining, the slurry is required to be free from precipitation, segregation, and bleeding. To improve the physical and mechanical properties of backfilling slurry and filling body, it is necessary to reduce the shrinkage and compression of the filling body. The methods to reduce the shrinkage and compression of the filling body are to reduce the bleeding rate and volume strain of the filling slurry and increase the volume concentration of the filling slurry, which is also the form of improving the physical and mechanical properties of the filling body. Therefore, it is necessary to study the material ratio, pumpability, filling equipment, and conveying distance.

\subsubsection{Optimization of Backfilling and Production Process.} Reasonable backfilling step and roof control distance are very important to the stability of the roof. The minimum roof control distance depends on the mining ventilation conditions, and the maximum roof control distance depends on the backfilling step. The longer the roof control time is, the longer the roof hanging time is, and the greater the roof subsidence is. Under the condition of three-mining- and 
TABLE 6: Weight of evaluation indicators.

\begin{tabular}{|c|c|c|c|c|c|}
\hline Criterion layer & $\begin{array}{l}\text { Weight } \\
\text { coefficient }\end{array}$ & $\begin{array}{l}\text { Quantitative/primary qualitative } \\
\text { indicators }\end{array}$ & $\begin{array}{c}\text { Weight } \\
\text { coefficient }\end{array}$ & $\begin{array}{c}\text { Secondary qualitative } \\
\text { indicators }\end{array}$ & $\begin{array}{l}\text { Weight } \\
\text { coefficient }\end{array}$ \\
\hline \multirow{8}{*}{$\begin{array}{l}\text { Mining geological } \\
\text { conditions }\end{array}$} & \multirow{8}{*}{0.15} & \multirow[t]{2}{*}{ Mining depth } & \multirow[t]{2}{*}{0.20} & Original rock stress & 0.54 \\
\hline & & & & Tectonic stress & $\begin{array}{l}0.46 \\
048\end{array}$ \\
\hline & & Coal seam & 0.21 & $\begin{array}{l}\text { Coal seam dip angle } \\
\text { Coal seam thickness }\end{array}$ & $\begin{array}{l}0.48 \\
0.52\end{array}$ \\
\hline & & Surface water drainage & 0.23 & & \\
\hline & & & & Strength of roadway & 0.31 \\
\hline & & Overburden structure & 0.36 & Key layer location & 0.34 \\
\hline & & & & Topsoil thickness & 0.35 \\
\hline & & & & Roof subsidence & 0.66 \\
\hline \multirow{5}{*}{$\begin{array}{l}\text { Approach of roof and } \\
\text { floor }\end{array}$} & \multirow{5}{*}{0.28} & Subsidence before filling & 0.36 & Floor heave & 0.27 \\
\hline & & & & Stress expansion & 0.07 \\
\hline & & Nonbackfilling account & 0.47 & & \\
\hline & & Floating coal & 0.12 & & \\
\hline & & Rock compression & 0.05 & & \\
\hline \multirow{7}{*}{ Filling body } & \multirow{7}{*}{0.32} & \multirow{2}{*}{ Volume shrinkage } & \multirow{2}{*}{0.17} & Bleeding rate & 0.45 \\
\hline & & & & Water content & 0.55 \\
\hline & & \multirow{2}{*}{ Volume compression } & \multirow{2}{*}{0.35} & Bulk concentration & 0.53 \\
\hline & & & & Volumetric strain & 0.47 \\
\hline & & \multirow{3}{*}{ Strength of filling body } & \multirow{3}{*}{0.48} & Poisson's ratio & 0.49 \\
\hline & & & & Elastic modulus & 0.51 \\
\hline & & & & Mining speed & 0.36 \\
\hline \multirow{6}{*}{$\begin{array}{l}\text { Mining and filling } \\
\text { technology }\end{array}$} & \multirow{6}{*}{0.17} & Mining technology & 0.33 & Support mode & 0.38 \\
\hline & & & & Coal pillar strength & 0.26 \\
\hline & & & & Filling step & 0.40 \\
\hline & & Filling technology & 0.47 & Unsupported roof span & 0.42 \\
\hline & & & & Filling sequence & 0.18 \\
\hline & & Slicing height & 0.20 & & \\
\hline \multirow{4}{*}{$\begin{array}{l}\text { Overburden retained } \\
\text { voids }\end{array}$} & \multirow{4}{*}{0.08} & Mining method & \multirow{2}{*}{0.38} & Strip mining & 0.67 \\
\hline & & Mining metnod & & Longwall mining & 0.33 \\
\hline & & Stratigraphic structure & 0.34 & & \\
\hline & & Surface structure & 0.28 & & \\
\hline
\end{tabular}

one-backfilling-cycle mode, the roof of the area to be filled has become a completely tensile state, and the risk of roof damage increases. Therefore, for the paste backfilling with $6 \mathrm{~m}$ large mining height and slicing mining, two-miningand one-backfilling-cycle mode is reasonable.

In addition, there are some subkey factors to control the surface subsidence of paste backfilling mining. For example, the height of slicing mining is optimized. When slicing mining, even if the mining height is $4 \mathrm{~m}$, the maximum roof approaching amount is about $300 \mathrm{~mm}$, which is also within the controllable range. In the later stage, the mining height can be adjusted appropriately according to the site conditions to increase the production of the working face. For example, strip mining instead of longwall mining can reduce the surface subsidence rate by 7.5 66.7\%, which makes more void volume stay in the overlying strata and controls the surface subsidence obviously. However, the compression of the roof and floor rock and floor floating coal can be ignored.

\section{Conclusions}

The research on the key factors affecting the surface subsidence of thick seam paste filling mining in deep mines is a complicated system engineering, which is a new exploration to liberate the coal resources under buildings combined with the mining conditions of the Lu'an mining area and has very important strategic significance. The main conclusions are as follows:

(1) A fuzzy extension model for the stability of surface subsidence caused by paste backfilling mining is established, and many factors of surface subsidence caused by paste backfilling mining are analyzed. The limitation of the traditional model which makes evaluation only from a qualitative or quantitative point of view is overcome, and the reliability grade of controlling surface subsidence caused by backfilling mining is "good." The key factors to control the surface subsidence are the overburden structure, the amount of roof subsidence before backfilling, nonbackfilling account, the strength of the filling body, and the backfilling technology. In addition, optimization suggestions in design and mining are given.

(2) It is preliminarily estimated that paste backfilling can make the recovery rate of $3 \#$ coal close to $80 \%$ in Gaohe coal mine, increase the recovery rate close to $40 \%$, liberate more than 210 million tons of coal resources under buildings, effectively extend the service life of the mine, and increase employment opportunities. Paste backfilling can effectively reduce 
the roof and floor damage scope and gas emission in goaf and improve the safety guarantee of coal mining. The main raw material of backfilling mining is coal gangue, which reduces the occupied land area of gangue while solving the problem of gangue discharge. Backfilling mining can protect groundwater resources and promote the ecological environment construction of mining areas.

\section{Data Availability}

The data used to support the findings of this study are included within the article. All the data are obtained through experiments and tested by our research team in Gaohe Mine and laboratory and are true and effective. The right to using data belongs to the authors before the article gets published, but the data can be referenced after publishing,.

\section{Conflicts of Interest}

The authors declare no conflicts of interest.

\section{Acknowledgments}

The authors would like to express their sincere thanks to all those who have helped writing this paper. They have done a lot of preliminary work in the related projects of the paper. Here the authors express their sincere thanks. Without their help, it would be much harder for the authors to finish this study. This paper was supported by Jiangsu University Natural Science Research Project (20KJB560032) and Jiangsu Construction System Science and Technology Project (Guidance) (2020ZD30, 2019ZD080, and 2019ZD070)

\section{References}

[1] T. Liu, Backfilling Mining Technology and Its Application, Metallurgical Industry Press, Beijing, China, 2001.

[2] A. Zhou, Cemented Backfilling of Mine Waste, Metallurgical Industry Press, Beijing, China, 2007.

[3] M. Zhang, Theoretical Study on Overburden Control of High Efficiency Paste Backfilling Working Face, China University of Mining and Technology, Xuzhou, China, 2019.

[4] X. Huang, "Leading energy industry reform with green development," People's Forum, vol. 31, pp. 26-27, 2017.

[5] R. Cowling, "Twenty-five years of mine filling-developments and directions," in Proceedings of the 6th International Symposium on Mining with Backfill, Brislane, Australia, Apri1 1998.

[6] M. Cullen, Geotechnical Studies of Retreat Pillar Coal Mining at Mining at Shallow Depth, McGill University, Montreal, Canada, 2002.

[7] K. B. Singh and T. N. Singh, "Ground movements over long wall workings in the Kamptee coalfield, India," Engineering Geology, vol. 50, no. 1, pp. 125-139, 1998.

[8] X. L. Yao, B. N. Whittaker, and D. J. Reddish, "Influence of overburden mass behavioral properties on subsidence limit characteristics," Mining Science and Technology, vol. 13, no. 2, pp. 167-173, 1991.
[9] M. Qian and P. Shi, Ground Pressure and Strata Control, China University of Mining and Technology Press, Xuzhou, China, 2003.

[10] M. Qian, "Structural model of overlying strata and its application," Journal of China University of Mining and Technology, vol. 2, no. 2, pp. 6-16, 1982.

[11] A. Philip, Engineering Design of Paste Backfill Systems, Queen's University Kingston, Kingston, Canada, 2003.

[12] X.-x. Miao, J.-x. Zhang, and M.-m. Feng, "Waste-filling in fully-mechanized coal mining and its application," Journal of China University of Mining and Technology, vol. 18, no. 4, pp. 479-482, 2008.

[13] Z. Song and J. Jiang, "Research focus and direction of coal mine strata control," Journal of Rock Mechanics and Engineering, vol. 15, no. 2, pp. 33-39, 1996.

[14] S. Widisinghe and N. Sivakugan, "Vertical stress isobars for trenches and mine stopes containing granular backfills," International Journal of Geomechanics, vol. 14, no. 2, pp. 313318, 2014.

[15] G. He and L. Yang, Mining Subsidence, China University of Mining and Technology Press, Xuzhou, China, 1994.

[16] L. Wu and J. Wang, Theory and Practice of Strip Mining under Buildings, China University of Mining and Technology Press, Xuzhou, China, 1994.

[17] K. Deng, "Application of rock mass structure effect in mining subsidence," Doctoral dissertation, China University of Mining and Technology, Xuzhou, China, 1993.

[18] W. Cai, C. Yang, and B. He, "Some problems in extenics research," Journal of Guangdong University of technology, vol. 18, no. 1, pp. 1-5, 2001.

[19] Y. Wang, "Extension fuzzy evaluation method for rock mass quality of underground mining engineering," Journal of Rock Mechanics and Engineering, vol. 21, no. 1, pp. 18-22, 2002.

[20] W. Cai, "The extension set and incompatibility problems," Journal of Scientific Exploration, vol. 1, no. 1, pp. 81-93, 1983.

[21] M. Kamber and J. Han, Data Mining Concepts and Techniques, Morgan Kaufmann Publishers, San Francisco, CA, USA, 2001.

[22] G. Stoilos, G. Stamou, J. Z. Pan, V. Tzouvaras, and I. Horrocks, "Reasoning with very expressive fuzzy description logics," Journal of Artificial Intelligence Research, vol. 30, no. 8, pp. 273-320, 2007. 